\title{
An Empirical Study on the Interdependence among Stock Market, Commodities Market and Foreign Exchange Market
}

\author{
*Dr. P. Sri ram \\ *Assistant Professor, Department of Commerce, Goa University, Goa - 403206
}

\begin{abstract}
Financial markets are full of imperfections, which make results inconsistent with the expectations. Genuine conditions apart, in the present world of finance, human greed, system failures or national afflictions can make things very unpredictable. This is where risk comes into play. Most of the investors have one simple approach to dealing with risk. That is to avoid it by all means. In financial investment matters, this may not be a good strategy. As risk and return are correlated, every risk you are avoiding possibly deprives you of a handsome opportunity to build your wealth. Balancing risk with return in line with individual circumstances is what financial market management is all about, is a question. So it becomes evident to establish a relationship between all the three markets namely stock, commodities and foreign exchange market. This is to find out additional ways of making investments. Thus, it becomes important to throw light upon the neglected areas of financial markets. The connection between a country's stock market, commodities market and its foreign exchange market has been a subject of theoretical and empirical investigation for many years. The nature and magnitude of the interdependence between stock prices, commodity prices and exchange rates have implications for a number of crucial issues in international finance. First there is the question of whether stock markets price, commodity prices have any implication on exchange rate and vice-versa. This study attempts to examine whether or not a causal relationship exists between commodities, exchange rates and stock market by using the Granger Causality and co-relation, relationships were determined for data between 2005 and 2014 in India.
\end{abstract}

\section{Introduction}

In an increasingly complex scenario of the financial world, it is of paramount importance for the researchers, practitioners, market players and policy makers to understand the working the analysis of dynamic and strategic interactions between stock, foreign exchange and commodities market came to the forefront because these two markets are the most sensitive segments of the financial system and are considered as the barometers of the economic growth through which the country's exposure towards the outer world is most readily felt.

Financial markets are full of imperfections, which make results inconsistent with the expectations. Genuine conditions apart, in the present world of finance, human greed, system failures or national afflictions can make things very unpredictable. This is where risk comes into play. Most of the investors have one simple approach to dealing with risk. That is to avoid it by all means. In financial investment matters, this may not be a good strategy. As risk and return are correlated, every risk you are avoiding possibly deprives you of a handsome opportunity to build your wealth. Balancing risk with return in line with individual circumstances is what financial market management is all about, is a question. So it becomes evident to establish a relationship between all the three markets namely stock, commodities and foreign exchange market. This is to find out additional ways of making investments. Thus, it becomes important to throw light upon the neglected areas of financial markets.

The connection between a country's stock market, commodities market and its foreign exchange market has been a subject of theoretical and empirical investigation for many years. The nature and magnitude of the interdependence between stock prices, commodity prices and exchange rates have implications for a number of crucial issues in international finance. First there is the question of whether stock markets price, commodity prices have any implication on exchange rate and vice- versa.

This study attempts to examine whether or not a causal relationship exists between commodities, exchange rates and stock market by using the Granger Causality and co-relation, relationships were determined for data between 2005 and 2014 in India.

\footnotetext{
Objectives

1. To find out the causal relationship between stock prices, commodity prices and exchange rates.

2. To evaluate the significant impact of each of the three markets on each other.

3. To study the impact of interdependence of each of the markets.
} 


\section{Literature Review}

For determining the relationship between stock exchange market commodities market and foreign exchange market various studies were undertaken by the researchers. Researchers used models like granger causality, GARCH $(1,1)$, vector autoregressive (VAR), Vector Error Correction Model (VECM), regression, multiregression for finding out relationship between stock market and foreign exchange market. The literature on the relationship between stock prices and exchange rates is very rich, but inconclusive. Frank and Young (1972) are considered to be the pioneers to investigate the relationship between exchange rates and stock prices. Their study concluded with the findings that the two variables have no significant relation. Soenen and Hennigar (1988) studied the same market but considered a different time period and contrast with prior studies by showing a significant negative relationship between stock prices and exchange rates.

Solnik (1987) made a slightly different study and tried to detect the impact of several economic variables including the exchange rates on stock prices. He concluded that changes in exchange rates do not have any significant impact over stock prices. Nieh and Lee (2001) supported the findings of BahmaniOskooee and Sohrabian (1992) and reported no long-run significant relationship between stock prices and exchange rates in the G-7 countries. Roll (1992) also studied the US stock prices and exchange rates and found a positive relationship between the two markets. Chow etal. (1997) examined the same markets but found no relationship between stock returns and real exchange rate returns. They repeated the exercise with a longer time horizons and found a positive relationship between the two variables. Abdalla and Murinde (1997) employed co-integration test to examine the relationship between stock prices and exchange rates for four Asian countries named as India, Pakistan, South Korea and Philippines for a period of 1985 to 1994. They detected unidirectional causality from exchange rates to stock prices for India, South Korea and Pakistan and found causality runs from the opposite direction for Philippines.

Yamini Karmarkar and G Kawadia tried to investigate the relationship between RS/\$ exchange rate and Indian stock markets. Five composite indices and five spectral indices were studied over the period of one year: 2000. The results indicated that exchange rate has high correlation with the movement of stock market. Wu (2000) did a similar study using stock prices and exchange rates of Singapore and portrayed a unidirectional causality from exchange rates to stock prices. Apte (2001) investigated the relationship between the volatility of the stock market and the nominal exchange rate of India by using the EGARCH specifications on the daily closing USD/INR exchange rate, BSE 30 (Sensex) and NIFTY-50 over the period 1991 to 2000. The study suggests that there appears to be a spill over from the foreign exchange market to the stock market but not the reverse. In a recent study.

Bhattacharya and Mukherjee (2003) investigated Indian markets using the data on stock prices and macroeconomic aggregates in the foreign sector including exchange rate concluded that there is no significant relationship between stock prices and exchange rates.

\section{Data Source and Variable Selection:}

\section{Research Methodology}

This study is based on secondary data collected from various sources. In order to achieve the objective of the research three variables are selected namely Stock Prices, Exchange Rate and Commodity Prices. The study is carried out using daily closing prices of COMDEX, CNX-NIFTY and daily exchange rate, from $3^{\text {rd }}$ April 2006 to $31^{\text {st }}$ March 2014, which covers 1092 daily observations. The data required is collected from various sources i.e. RBI publications, MCX and NSE websites, and BLOOMBERG data files.

\section{Defining Variables Of The Study}

\section{A. Dependent Variable - Foreign Exchange Market}

The market for foreign exchange involves the purchase and sale of national currencies. A foreign exchange market exists because economies employ national currencies. If the world economy used a single currency there would be no need for foreign exchange markets.

\section{B. Explanatory Variables \\ a. Stock Market.}

Secondary market refers to a market where securities are traded after being initially offered to the public in the primary market and/or listed on the Stock Exchange. Majority of the trading is done in the secondary market. Secondary market comprises of equity markets and the debt markets. The secondary market enables participants who hold securities to adjust their holdings in response to changes in their assessment of risk and return. They also sell securities for cash to meet their liquidity needs.

The stock market is a market for financial investments that are direct or indirect claims to capital. It is wider than the Securities Market and embraces all forms of lending and borrowing, whether or not evidenced by the creation of a negotiable financial instrument. The Capital Market comprises the complex of institutions 
and mechanisms through which intermediate term funds and long-term funds are pooled and made available to business, government and individuals. The Capital Market also encompasses the process by which securities already outstanding are transferred

This study has analyzed whether there exists a relationship between the stock market, commodities market and foreign exchange market. The variables taken for the study are CNX NIFTY closing prices, MCX COMDEX closing prices and the exchange rate .For the analysis of the variables regression analysis has been used to find out its interrelationship with each other. Further, the hypothesis has been formulated for testing the significance of the model. Granger causality model has been used to find out the causal relationship between the variables; also Augmented Dickey-Fuller unit root tests have been used to test if the data available is stationary and at what level. Finally, the covariance matrix has the developed to find the interrelation of the three markets with each other.

\section{Hypothesis Testing}

Commodities Market

$\mathrm{H}_{0 \text { : }}$ Commodities market impact foreign exchange market

$\mathrm{H}_{1:}$ Commodities market does not impact foreign exchange market

Stock Market

$\mathrm{H}_{0 \text { : }}$ Stock market impact foreign exchange market

$\mathrm{H}_{1:}$ Stock market does not impact foreign exchange market

\section{Regression Analysis}

The following Regression analysis explains the relationship between the dependent variable foreign exchange market and independent variables of stock market and commodities market.

Table -1: Regression Model

Model 1: OLS, using observations 1-1904 ( $\mathrm{n}=1903)$

Missing or incomplete observations dropped: 1

Dependent variable: Exchange__Rate

Heteroskedasticity-robust standard errors, variant $\mathrm{HC1}$

\begin{tabular}{|l|l|l|l|l|l|}
\hline & Coefficient & Std. Error & t-ratio & $p$-value & \\
\hline Const & 36.3664 & 0.508315 & 71.5430 & $<0.00001$ & $* * *$ \\
\hline Stock_market & -0.00252992 & 0.000122715 & -20.6162 & $<0.00001$ & $* * *$ \\
\hline Commodities_mar & 0.00822595 & 0.000159688 & 51.5127 & $<0.00001$ & $* * *$ \\
\hline
\end{tabular}

\begin{tabular}{|l|l|l|l|l|}
\hline Mean dependent var & 48.43895 & & S.D. dependent var & 6.275664 \\
\hline Sum squared resid & 31900.02 & & S.E. of regression & 4.097497 \\
\hline R-squared & 0.574146 & & Adjusted R-squared & 0.573697 \\
\hline F(2, 1900) & 1377.424 & & P-value(F) & 0.000000 \\
\hline Log-likelihood & -5382.685 & & Akaike criterion & 10771.37 \\
\hline Schwarz criterion & 10788.02 & & Hannan-Quinn & 10777.50 \\
\hline
\end{tabular}

\section{Analysis and Interpretation}

This model summary reports the strength of the relationship between the model and the dependent variable. $\mathrm{R}$, the multiple correlation coefficients, is the linear correlation between the observed and model predicted values of the dependent variable. Its large value indicates a strong relationship. $\mathrm{R}$ Square, the coefficient of determination, is the squared value of the multiple correlation coefficients.

Here the value of R2 ( $\mathrm{R}$ squared) is 0.5741 ; it shows that the model explains $57.41 \%$ of the variation. In other words the independent variables are able to explain around $57.41 \%$ of the variation of the dependent variable. As the $r^{2}$ is close to 1 , it will be useful in making predictions. It means that the independent variables of stock market and commodities market cause a change in the exchange rate by $57 \%$ and the rest is explainer by other factors, which shows it is a good model to show the interdependence between these three markets. The adjusted R-square, a measure of explanatory power, is 0.573697 . This statistic is not generally interpreted because it is neither a percentage (like the $\mathrm{R}^{2}$ ), nor a test of significance (such as the F-statistic). From the coefficient values of stock market and commodities market it can be interpreted that $1 \%$ change in stock market causes $-0.0025 \%$ change in the exchange rate and $1 \%$ changes in the commodities market causes $0.0082 \%$ change in the exchange rate. Also it shows that dependent variable causes a negative change in the stock market, whereas it subsequently causes a negative change in the commodities market. 


\section{Correlation Matrix}

The following covariance matrix has been estimated to study the interrelationship between the stock market, commodities market and foreign exchange market.

Table -2: Correlation Matrix

\begin{tabular}{|l|l|l|l|}
\hline & COMMODITIES_MARKET & EXCHANGE_RATE & STOCK_MARKET \\
\hline COMMODITIES_MARKET & 1 & 0.711843 & 0.745439 \\
\hline EXCHANGE_RATE & 0.711843 & 1 & 0.35755 \\
\hline STOCK_MARKET & 0.745439 & 0.35755 & 1 \\
\hline \hline
\end{tabular}

\section{Analysis and Interpretation}

The correlation matrix measures the degree which two variables change or vary together. The above matrix displays the interrelationship between the select markets with one another. According to the matrix, the macroeconomic variables either have positive or negative interrelationship amongst them and none of them displaying linear dependency. There is highest positive correlation relation between the commodities market and stock market compared to other pairs. From the above table 5.3.1 it can be explained that the commodities market and stock market are highly correlated by $74.54 \%$, whereas exchange rate and commodities market are correlated to an extent of $71.18 \%$.

\section{Augmented Dickey-Fuller Test (ADF)}

To check the stationarity and if there is presence of unit root in the series, the most famous of the unit root tests are the ones derived by Dickey and Fuller and described in Fuller (1976), also Augmented DickeyFuller (ADF) or said-Dickey test has been mostly used.

A time series is said to be stationary if its mean and variance are constant over time and the value of the covariance between the two time periods depends only on the distance or gap or lag between the two time periods and not the actual time at which the covariance is computed. Test for stationarity is important in case of time series data because a non stationary time series will have time varying mean or a time-varying variance or both. Hence the results cannot be extrapolated for the entire population. The test for stationarity can be done using Unit Root Test.

Since all time series data sets contain either deterministic or stochastic trends (or both), unit root tests and stationarity tests are a way of determining which kind of trends are present in the data. If only deterministic trends are present, then the series can be seen as being generated by some non-random, predetermined function of time with some random error thrown in.

Table -3: Unit root test of Commodities Market (MCX COMDEX)

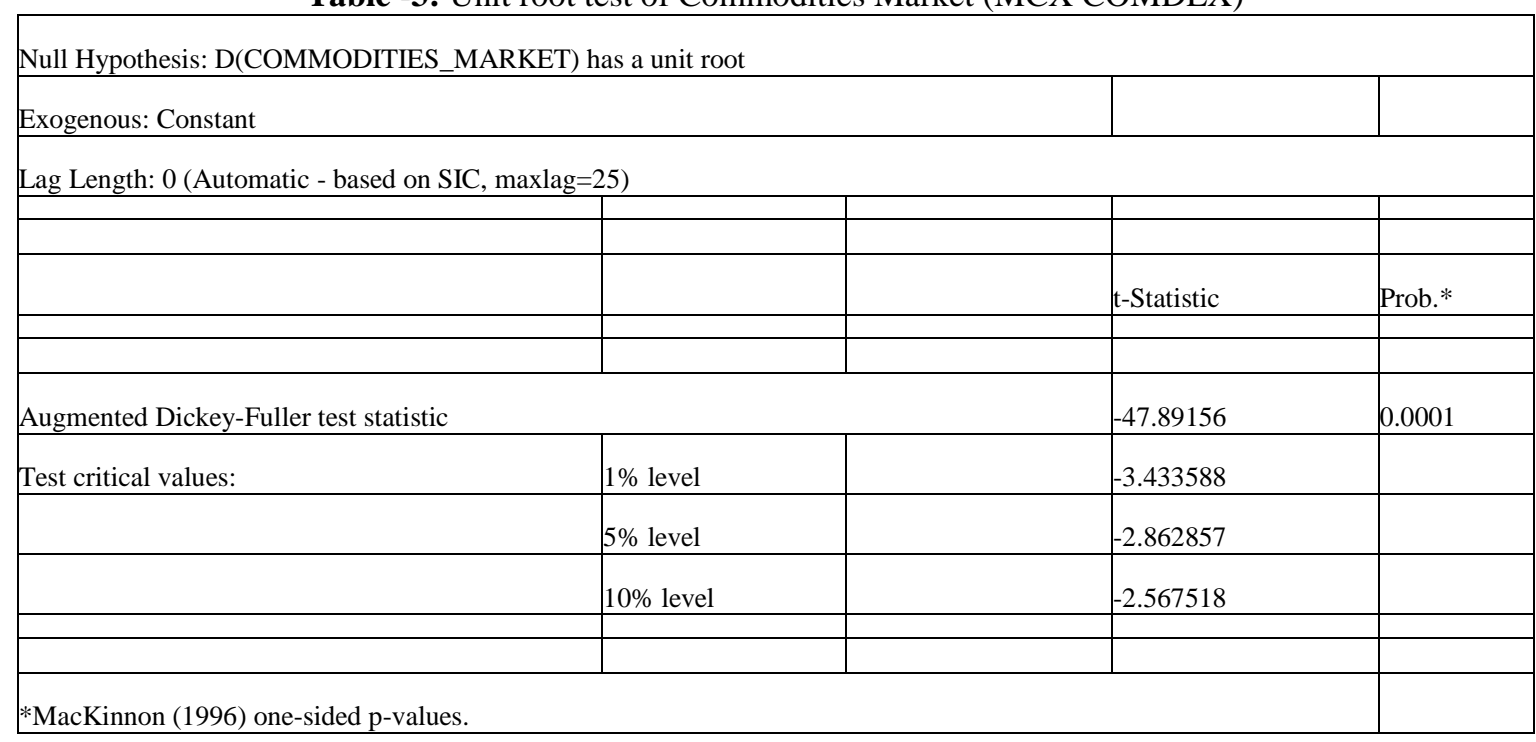

\section{Analysis and Interpretation}

In the sample time series data i.e., CNX NIFTY, MCX COMDEX and exchange Rate, Rs/\$ data have been tested for their stationarity. The results are given in Table 3. In the analysis while testing for stationarity of MCX COMDEX prices, we find that the prices are not stationary at levels. Further at first difference, $p$ value is less than the required $5 \%$ criteria or 0.05 . Hence it can be conclude that the data set (MCX COMDEX) is stationary at first difference. 
An Empirical Study on the Interdependence among Stock Market, Commodities Market and ..

Table -4: Unit root test of Exchange Rate (Rs./\$)

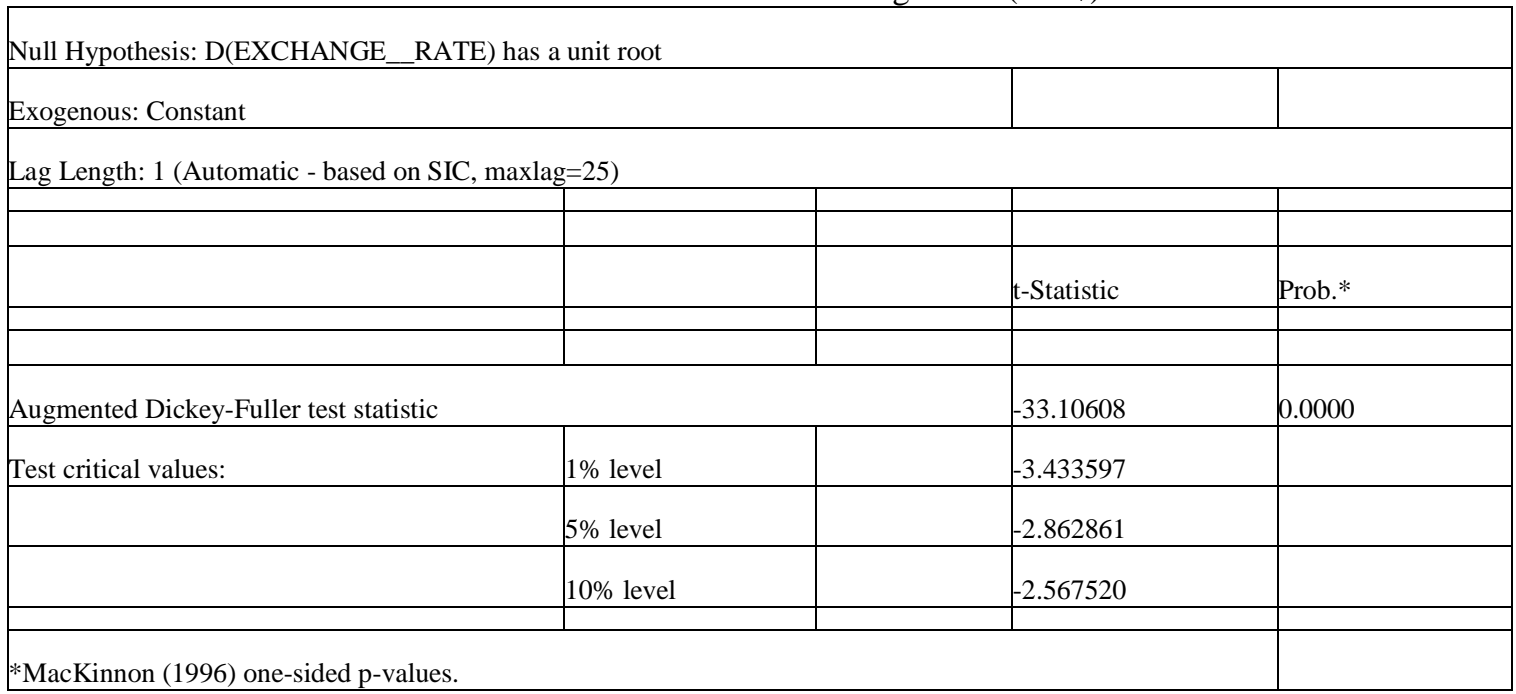

\section{Analysis and Interpretation}

In the same way Exchange rates was also tested for the presence of unit root problem. The results are given in Table 4. In the analysis we find that exchange rates are not stationary at levels. Further at first difference, the $\mathrm{p}$ value is less than the required $5 \%$ criteria or 0.05 . Hence it can be conclude that the data set (exchange rate Rs./\$) is stationary at first difference.

Table -5 : Unit root test of Stock Market ( CNX NIFTY)

\begin{tabular}{|l|l|l|l|l|}
\hline Null Hypothesis: D(STOCK_MARKET) has a unit root & & \\
\hline Exogenous: Constant & & & & \\
\hline Lag Length: 0 (Automatic - based on SIC, maxlag=25) & & & \\
\hline & & & t-Statistic & Prob.* \\
\hline & & & & \\
\hline & & & -40.73768 & 0.0000 \\
\hline Augmented Dickey-Fuller test statistic & $1 \%$ level & & -3.433588 & \\
\hline Test critical values: & $5 \%$ level & & -2.862857 & \\
\hline & $10 \%$ level & & -2.567518 & \\
\hline & & & & \\
\hline
\end{tabular}

\section{Analysis and Interpretation}

In the analysis while testing for stationarity of CNX Nifty prices, we find that the prices are not stationary at levels. Further at first difference, p value is less than the required 5\% criteria or 0.05 . Hence it can be conclude that the data set (CNX Nifty) is stationary at first difference.

\section{Granger Causality Test}

Granger proposed the idea of Granger-causality in his 1969 paper to describe the 'causal relationship between variables in econometric models. Before this, econometricians and economists understood the idea of 'causal relationships' as asymmetrical relationships. Causal relations are studied because policy makers need to know the consequences of the various actions which they will or are considering taking. For example; given a relationship between output and the price level, we need to know whether this relationship is expected to hold if actions controlling output are implemented, when actions controlling the price level are implemented, or when both of these cases occur. 
An Empirical Study on the Interdependence among Stock Market, Commodities Market and ..

Table 6: Granger Causality Test between Exchange Rate, Nifty and COMDEX

\begin{tabular}{|c|c|c|c|}
\hline \multicolumn{4}{|c|}{ Pairwise Granger Causality Tests } \\
\hline \multicolumn{4}{|l|}{ Date: $04 / 10 / 14$ Time: $12: 56$} \\
\hline \multicolumn{4}{|l|}{ Sample: 4/03/2006 7/18/2013 } \\
\hline \multicolumn{4}{|l|}{ Lags: 4} \\
\hline Null Hypothesis: & Obs & F-Statistic & Prob. \\
\hline EXCHANGE_RATE does not Granger Cause COMMODITIES_MARKET & 1895 & 3.84531 & 0.0041 \\
\hline COMMODITIES_MARKET does not Granger Cause EXCHANGE_RATE & & 2.80269 & 0.0246 \\
\hline STOCK_MARKET does not Granger Cause COMMODITIES_MARKET & 1900 & 0.42660 & 0.7895 \\
\hline COMMODITIES_MARKET does not Granger Cause STOCK_MARKET & & 2.64922 & 0.0318 \\
\hline STOCK_MARKET does not Granger Cause EXCHANGE_RATE & 1895 & 1.18058 & 0.3174 \\
\hline EXCHANGE_RATE does not Granger Cause STOCK_MARKET & & 25.2557 & 2.E-20 \\
\hline
\end{tabular}

\section{Analysis and Interpretation}

Hypothesis

- Null hypothesis (H01) : Commodities Market does not granger cause exchange rate

- Second null hypothesis (H02) : Stock market does not granger cause Commodities Market

- Third null hypothesis (H03) : Stock market does not granger cause Exchange Rate.

Thus, reject the null hypothesis' and accept the alternate hypothesis, i.e. exchange rate granger causes commodities market, commodities market granger causes stock market and exchange rate granger causes stock market since the probability values for the alternate hypothesis is less than 0.05 .

The Granger-causality test is applied in order to test the relationship between exchange rates commodity prices and stock prices. The test results of Granger-causality of the three variables are given in the table 5.5.1. In order to capture the degree and the direction of long term correlation between Nifty prices, COMDEX prices and exchange rate under study, Granger Causality Test was conducted. From the statistics given in the table, we can deduce that Nifty does not granger cause Exchange rates when Exchange rates is the dependent variable, since the p value 0.3174 is much higher than the required 0.05 or $5 \%$. Hence we reject null hypothesis $\mathrm{H}(03)$. Thus it can be said that the coefficients of Nifty does not affect the future performance of Exchange rates. In the case of direction between Exchange Rates and Nifty, where Nifty is the dependent variable, the $\mathrm{p}$ value is $2 . \mathrm{E}-20$ which is less than 0.05 or the $5 \%$ significance level. Thus granger causality has been identified between Exchange rates to Nifty. Hence we can accept alternate hypothesis of exchange rate causing stock market. If relation between foreign exchange market and stock market exist, then it is possible that investors may use this information to predict the exchange rate movement or indices movement.

Also, we can reject second null hypothesis that, Stock market does not granger cause Commodities Market since the $\mathrm{p}$ values are 0.7895 which is way higher than 0.05 . Thus, we can accept the alternate hypothesis of commodities market causes stock market since its $\mathrm{p}$ values is 0.0318 which is less than 0.05 .

Thus, we can say that there exists relationship between exchange rate and stock market and also between commodities market and stock market respectively and subsequently cause and have an impact on each other.

\section{Findings and Conclusions}

By analysing the daily data, the dynamic relationship between stock prices commodity prices and exchange rates in India have been examined. The main concerns were to examine whether there exists a relationship between these three markets and whether they have any impact on each other.

The following conclusions have been derived from the analysis:

The results of the regression analysis include estimated coefficients, the standard error of the coefficients, the calculated t-statistic and the corresponding p-value. The independent variables that are statistically significant in explaining the variation in the exchange rates are stock market and commodities market in India as indicated by calculated t-statistics that exceed the critical values, and the calculated p-values that are less than the significance level of $1 \%$.

The relationship between exchange rate and commodities market is positive according to the model which means that when there is $1 \%$ change in commodities market there is a subsequent change of 
$0.00822595 \%$ change in the exchange rate. Whereas the relationship between exchange rate and stock market is negative according to the model since the coefficient value is -0.00252992 . This means that, $1 \%$ change in stock market brings about $-0.00252992 \%$ change in the exchange rate which is a dependent variable. It is found that from the correlation matrix that the commodities market and stock market are highly correlated by $74.54 \%$, whereas exchange rate and commodities market are correlated to an extent of $71.18 \%$. Also, the CNX Nifty, MCX COMDEX and exchange rate data is found to be stationary at first difference and not at levels. It was found that there is a causal relationship between exchange rate and stock market and exchange market and commodities market respectively.

\section{References}

[1]. Harberger, A. (2004), Economic Adjustment and the Real Exchange Rate, in S. Edwards and L.Ahamed (eds.), Economic Adjustment Exchange Rates in Developing Countries", University of Chicago Press, 10, 308-321

[2]. Husain, A.M., Mody, A., Rogoff, K.S., (2004), "Exchange Rate Regime Durability and Performance in Developing Versus Advanced Economies", Journal of Monetary Economics, 52(1), 35-64.

[3]. Mishra, A., and Yadav, R. (2012). Exchange Rate Behaviour and Management In India: Issues And Empirics. International Journal of Economics, Commerce and Research, 2 (4), 9-16.

[4]. Raithatha, M. (2012). A Conceptual Study On Fluctuation Of Rupee In Relation To Dollar. ZENITH International Journal of Business Economics and Management Research, 2 (3), 266-274.

[5]. Hooper, P., and Morton, J. (1982). Fluctuations in the Dollar: A Model of Nominal and Real Exchange Rate Determination. Journal of International Money and Finance, 1, 39-56

[6]. Mita H Suthar,(2006), Bank Rate and Interest Yield Differentials as Determinants of Foreign Exchange Rate in India, ICFAI Monetary Economics,44-49 